\title{
Flow and heat transfer of petal-shaped double tube (Water and air-water bubbly flow)
}

\author{
Toshihiko SHAKOUCHI*, Ryosuke OZAWA*, Koichi TSUJIMOTO* and Toshitake ANDO* \\ *Graduate School of Engineering, Mie University \\ Kurimamachiya-cho 1577, Tsu-shi, Mie 514-8507, Japan \\ E-mail:shako@mach.mie-u.ac.jp
}

Received 29 February 2016

\begin{abstract}
Heat exchangers are widely used for heating, cooling, evaporation, and condensation. There are many types of heat exchangers, shell and tube, fin tube, and double tube heat exchangers. Double tube heat exchangers show high performance, and several modifications have been made with regard to their pipe geometry to further improve their performance. A petal-shaped double tube with a large wetted perimeter is one such example. The working fluid of a heat exchanger for the evaporator and condenser of an air-conditioner or boiler may become a gas-liquid two-phase flow with phase change. In this study, the flow and heat transfer characteristics of airwater bubbly flow through a petal-shaped double tube with a large wetted perimeter are examined experimentally and compared with those of a conventional circular double tube. The experiments employed two petal-shaped double tubes: one with six petals and another with five petals. This study explains for single-phase water and two-phase air-water bubbly flows. The heat transfer characteristics are studied by measuring the temperature distributions in the inner and outer pipes by a thermo couple. The study also clarifies the effects of air bubbles on heat transfer performance.
\end{abstract}

Key words : Heat transfer, Heat exchanger, Double tube heat exchanger, Petal-shaped double tube, Bubbly flow, Pressure loss, Heat transfer performance

\section{Introduction}

A heat exchanger is a device that transfers heat from one fluid to another. Heat exchangers are widely used for heating, cooling, evaporation, and condensation. There are many types of heat exchangers, including shell and tube, fin tube, and double tube heat exchangers.

Double tube heat exchangers show high performance, and several modifications have been made with regard to their pipe geometry to further improve of their performance (Shakouchi, et al., 2012, 2015). Kimura \& Ito (1981) reported the heat transfer characteristics of a tube with spiral grooves on the inner surface. Nagashima, et al. (2010) discussed the heat transfer characteristics of a double tube with a multi-leaf-like inner pipe. Fuskele \& Sarviya (2012) and Promonvonge, et al. (2012) investigated a twisted tape inserted in a pipe, as a turbulence promoter, on the heat transfer.

A petal-shaped double tube with a large wetted perimeter is a modification made to improve heat transfer in double tube heat exchangers. Furthermore, the working fluid of the heat exchanger for the evaporator and condenser of an air-conditioner or boiler may become a gas-liquid two-phase flow with phase change.

In this study, the flow and heat transfer characteristics of air-water bubbly flow through a petal-shaped double tube with a large wetted perimeter are examined experimentally compared with those of a conventional circular double tube. 
The experiments employed two petal-shaped double tubes: one with six petals and another with five petals. The study helped understand the heat transfer characteristics of counter flow heat exchangers for single-phase water and two-phase air-water bubbly flows. The heat transfer characteristics were studied by measuring the temperature distributions in the inner and outer pipes by a thermo couple. The study also clarified the effects of air bubbles on heat transfer performance.

\section{Experimental apparatus and procedure}

\subsection{Experimental apparatus}

Figure 1 shows the schematic diagram of the double tube used in the experiment. The tube made of copper, has a total length of $2.4 \mathrm{~m}$. It comprises inner and outer pipes that are pressed against each other, and are set vertically.

The test section of originates at a position of $230 \mathrm{~mm}$ downstream from the inlet of the inner pipe. The $x$-coordinate is downstream from the inner pipe, whereas the $r$-coordinate is in the direction perpendicular to the $x$-coordinate.

Hot water or air-water bubbly flow at a temperature of $60^{\circ} \mathrm{C}$ flows upward through the inner pipe, whereas cold water at a temperature of $20^{\circ} \mathrm{C}$ flows through the outer pipe forming the counter flow. The inlet of the inner pipe is inclined at angle of $30^{\circ}$ to ensure equal rate of flow through each outer pipe (Shakouchi, et al., 2012, 2015).

Sample temperature data was collected at positions (4) and (7) $(L=1.4 \mathrm{~m})$ in the fully developed flow region both the inner and outer pipes. The temperatures were measured using $\mathrm{Cu}$-Co thermo-couples, and the bulk temperature and logarithmic mean temperature difference were calculated. The pressure loss between positions of (6) and (7) in the fully developed flow region was measured using pressure holes with a diameter of $0.8 \mathrm{~mm}$ and manometer.

Figure 2 shows the schematic diagram of the entire experimental apparatus. The air-water bubbly flow is generated

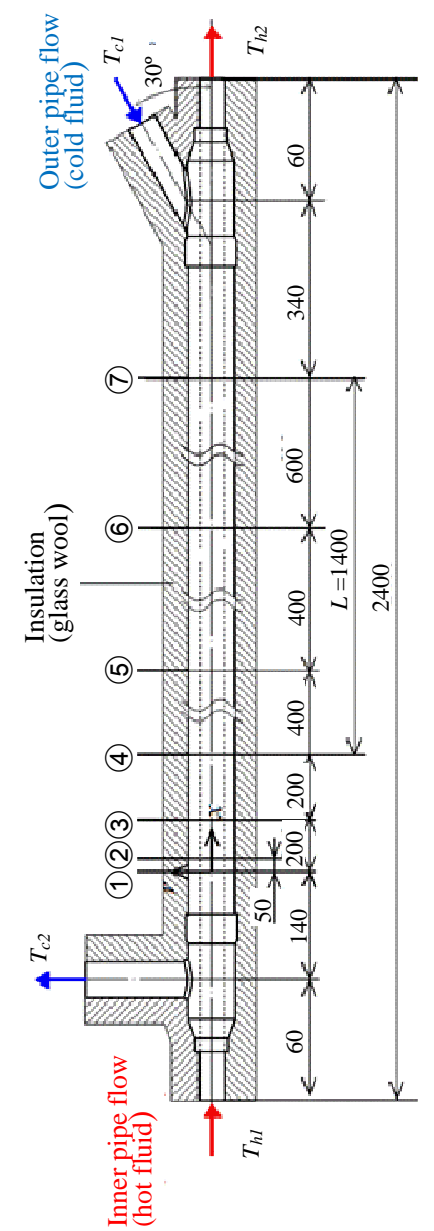

Fig.1 Test section, double tube

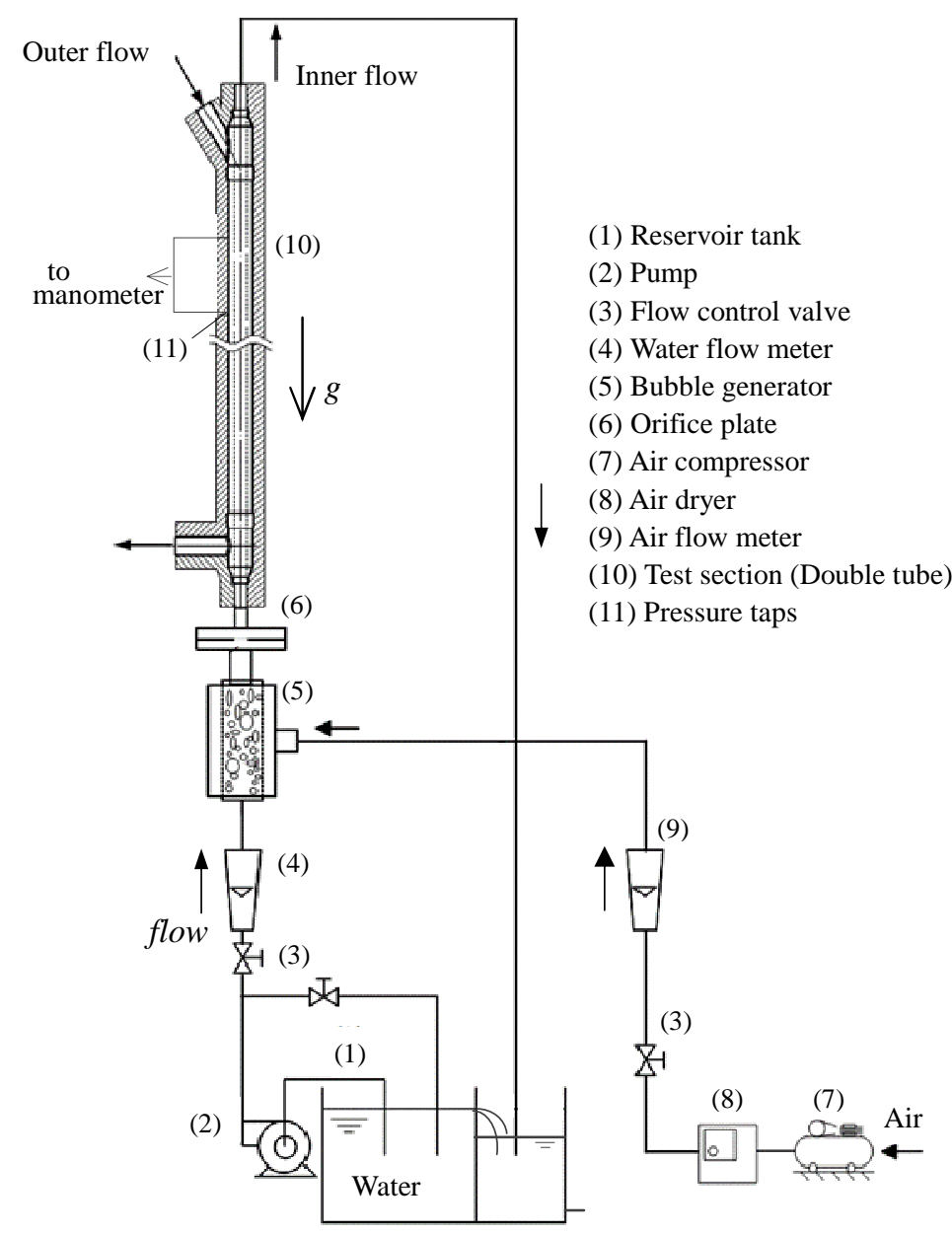

Fig.2 Experimental apparatus 
by passing air through the bubble generator (5) made of a fine ceramic porous medium, and the orifice plate (6). Further, the mean size of the bubble changed from $2.0 \mathrm{~mm}$ to $3.98 \mathrm{~mm}$.

\subsection{Shape of double tube}

Figure 3 shows the cross sections of the petal-shaped double tubes with six and five petals, hereafter referred to as the 6P- and 5P-tube, respectively. A conventional circular double tube, hereafter referred to as a CP-tube, with the same inner cross-sectional area as that of the 6P-tube was also used for comparison. This is because the hydraulic diameter of the $6 \mathrm{P}$-tube is very small $\left(d_{i n, h}=5.1 \mathrm{~mm}\right)$ owing to a large wetted perimeter, and the size is unnaturally small.

The cross-sectional area, perimeter, circle equivalent diameter and hydraulic diameter of the inner pipe in the $6 \mathrm{P}$ tube are $A_{i n}=124 \mathrm{~mm}^{2}, p_{i n}=96.47 \mathrm{~mm}, d_{i n, e}=\left(4 A_{i n} / \pi\right)^{1 / 2}=12.5 \mathrm{~mm}$ and $d_{i n, h}=4\left(A_{i n} / p_{i n}\right)=5.1 \mathrm{~mm}$, respectively. For the outer pipe in the $6 \mathrm{P}$-tube, these values are $A_{\text {out }}=108 \mathrm{~mm}^{2}, p_{\text {out }}=120 \mathrm{~mm}, d_{\text {out }, a}=11.7 \mathrm{~mm}$ and $d_{\text {out }, h}=3.6 \mathrm{~mm}$, respectively. These values for the inner pipe in the 5P-tube are $A_{\text {in }}=131 \mathrm{~mm}^{2}, p_{\text {in }}=71.2 \mathrm{~mm}, d_{\text {in,e }}=\left(4 A_{\text {in }} / \pi\right)^{1 / 2}=12.9 \mathrm{~mm}$ and $d_{i n, h}=4\left(A_{i n} / p_{\text {in }}\right)=7.3 \mathrm{~mm}$, respectively. For the outer pipe in the 5P-tube, these values are $A_{\text {out }}=130 \mathrm{~mm}^{2}, p_{\text {out }}=$ $121.4 \mathrm{~mm}, d_{\text {out }, e}=12.9 \mathrm{~mm}$ and $d_{\text {out }, h}=4.3 \mathrm{~mm}$, respectively.

The wetted perimeter of the petal-shaped inner tube is considerably large, which makes the hydraulic diameter $\left(d_{i n, h}\right.$ $\left.=4\left(A_{i n} / p_{i n}\right)=5.1 \mathrm{~mm}\right)$ too small. Hence, inner pipe with an equivalent diameter of $d_{i n, e}=12.5 \mathrm{~mm}$ for the $6 \mathrm{P}$-inner tube was tested as a conventional double tube for comparison [see Fig.3(c)].

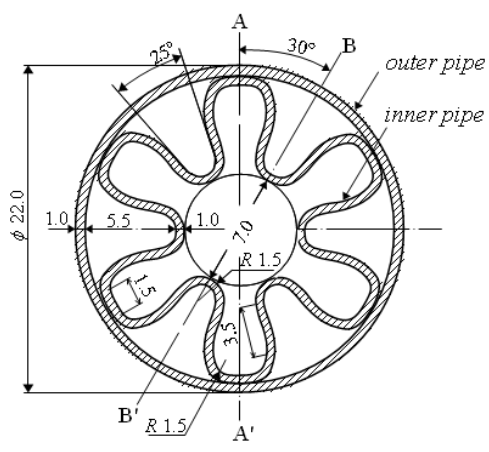

(a) 6P-tube

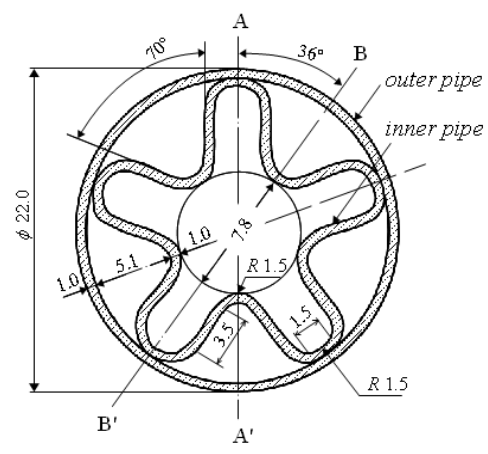

(b) 5P-tube

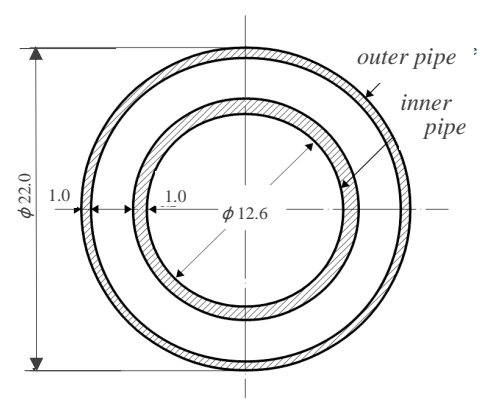

(c) CP-tube

Fig. 3 Cross section of double tube

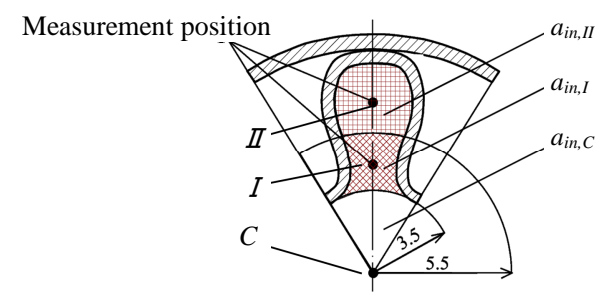

(a) Inner pipe

$$
\left\{\begin{array}{l}
a_{i n, c}=38.5\left[\mathrm{~mm}^{2}\right], \quad a_{i n, I}=33.5\left[\mathrm{~mm}^{2}\right], \\
a_{i n, I I}=52.0\left[\mathrm{~mm}^{2}\right]
\end{array}\right.
$$

Fig.4 Positions of thermo couples at (4) and (7) of 6P-tube in Fig.1

\subsection{Heat transfer}

After measuring the flow rate, hot water at a temperature of $60^{\circ} \mathrm{C}$ was introduced from a water tank into the petal-shaped inner pipe, using a pump. Cold water at a temperature of $20^{\circ} \mathrm{C}$ was made to flow through the outer pipe. The outer pipe was covered with an insulator. As shown in Figure 1, the $\mathrm{Cu}$-Co thermo couples were located at the centre of the inner and outer pipes, at positions (1) and (7) in Figure 1. In order to estimate the bulk temperature $T_{b}$ at positions (4) and (7), more two thermo couples at two positions as shown in Figure 4. The bulk temperature can be expressed as 


$$
T_{b}=T_{c}\left(m_{c} / m_{\text {all }}\right)+T_{I}\left(m_{I} / m_{\text {all }}\right)+T_{I I}\left(m_{I I} / m_{\text {all }}\right)
$$

where, $\{m$ : mass flow rate

subscript, $c, I, I I$, all $(=c+I+I I)$ : position (see Fig.4)

The mass flow rate $m_{c}, m_{I}$ and $m_{I I}$ through each sub-domain was approximated as the product of the mean velocity and the area of each sub-domain (Ozawa, 2015).

Since it was difficult to measure the velocity distribution at the cross section in the petal shaped double tube it was approximated by measurements of the velocity distribution just after the petal shaped double tube nozzle which was prepared particularly. The nozzle has an enough length to ensure a fully developed flow. The measurement was carried out for air jet flow issued from the petal shaped double tube nozzle by a hot wire anemometry under the same Reynolds number of the water flow.

The mean velocity of each sub-domain was approximated using the velocity distribution at the cross section A-A' and B-B' in Figure 3. The difference between the total flow rate known and the flow rate obtained the above method was corrected in proportion to the area of each sub-domain.

The heat transfer $Q_{\text {in }}$ between positions (4) and (7) can be expressed as

$$
Q_{\text {in }}=\left\{\frac{m_{w}(100-x) c_{p_{w}}+m_{a} x c_{p_{a}}}{100}\right\} \Delta T_{m}
$$

where, $c_{p}:$ specific heat

$\Delta T_{m}$ : logarithmic mean temperature difference $\left[=\left(\Delta T_{1}-\Delta T_{2}\right) / \ln \left(\Delta T_{1} / \Delta T_{2}\right)\right]$

$\Delta T_{1}=T_{h 1}-T_{c 2,} \Delta T_{2}=T_{h 2}-T_{c l}$

$T_{h 1}, T_{h 2}$ : bulk temperature at positions (4) and (7), respectively, in inner pipe

$T_{c l}, T_{c 2}$ : bulk temperature at positions (7) and (4), respectively, in outer pipe

$x$ : quality

subscript, $w, a:$ water, air

The mean Nussselt number, $N u$, can be expressed as

$$
N u=h_{i} d_{i n, h} / k_{i}
$$

where, $\left\{h_{i}\right.$ : heat transfer coefficient

$k_{i}$ : thermal conductivity of water flow

In this study, the heat transfer coefficient was obtained by Wilson plot method (Rose, 2004).

\section{Results and discussion}

\subsection{Flow pattern of bubbly flow}

Here, only the flow situation of bubbly flow is shown for reference.

Figure 5 shows the flow pattern of bubbly flow at Reynolds number $R e=u_{w} d / v=5.0 \times 10^{3}$ in the pipe a diameter $d$ $=30.0 \mathrm{~mm}$. Here, $u_{w}$ is the mean velocity of water flow, and $\alpha$, apparent void fraction, is the ratio of the volumetric flow rate of air $Q_{a}$ to that of the mixture. The apparent void fraction can be expressed as $\alpha=Q_{a} /\left(Q_{a}+Q_{w}\right)$. Increasing the apparent void fraction from $2.5 \%$ to $15 \%$ resulted in an increase in the mean bubble size $d_{b m}$ from $2.0 \mathrm{~mm}$ to 3.12 


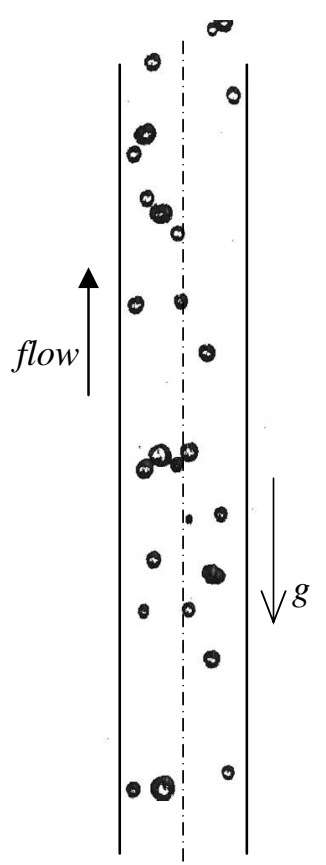

(a) $\alpha=2.5 \%$ $d_{b m}=2.0 \mathrm{~mm}$

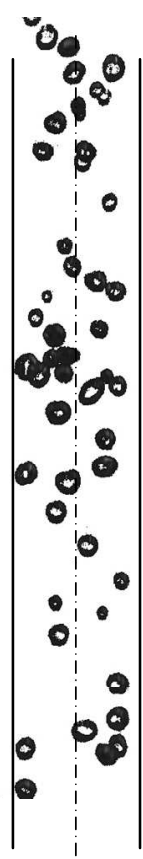

(b) $\alpha=5.0 \%$ $d_{b m}=2.28 \mathrm{~mm}$

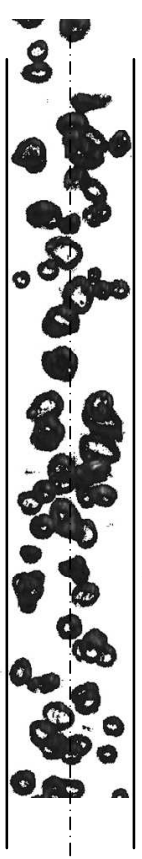

(c) $\alpha=10.0 \%$ $d_{b m}=2.66 \mathrm{~mm}$

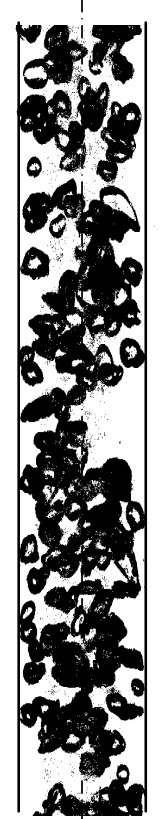

(d) $\alpha=15.0 \%$

$d_{b m}=3.12 \mathrm{~mm}$

Fig.5 Visualized flow pattern of two-phase bubbly flow $\left(\operatorname{Re}=5.0 \times 10^{3}\right)$

$\mathrm{mm}$. The circle-formed things in Figure 5 denote bubbles. The mean bubble size was obtained by using a visualized flow pattern, image processing software and PC (Ozawa, 2015). At a high Reynolds number of $R e=1.0 \times 10^{4}$, the mean bubble size increased from $2.77 \mathrm{~mm}$ for $\alpha=2.5 \%$ to $3.98 \mathrm{~mm}$ for $\alpha=15 \%$.

\subsection{Flow resistance, pressure drop, $\Delta p$}

Figure 6 shows the relationship between the flow resistance, pressure losses in the inner and outer pipes of the CP-tube ( $\Delta p_{C P, \text { in }}$ and $\Delta p_{C P, \text { out }}$, respectively), and the mean velocity $u_{m}$. For single-phase water flow $(\alpha=0.0 \%), \Delta p$ decreases exponentially with decreasing $u_{m}$ and can be expressed as

$$
\Delta p_{C P, \text { in }}=1090 u_{m}^{1.71}, \quad \Delta p_{C P, \text { out }}=2680 u_{m}^{1.77}
$$

where, $\Delta p_{C P, \text { in }}, \Delta p_{C P, \text { out }}:[\mathrm{Pa} / \mathrm{m}], u_{m}:[\mathrm{m} / \mathrm{s}]$

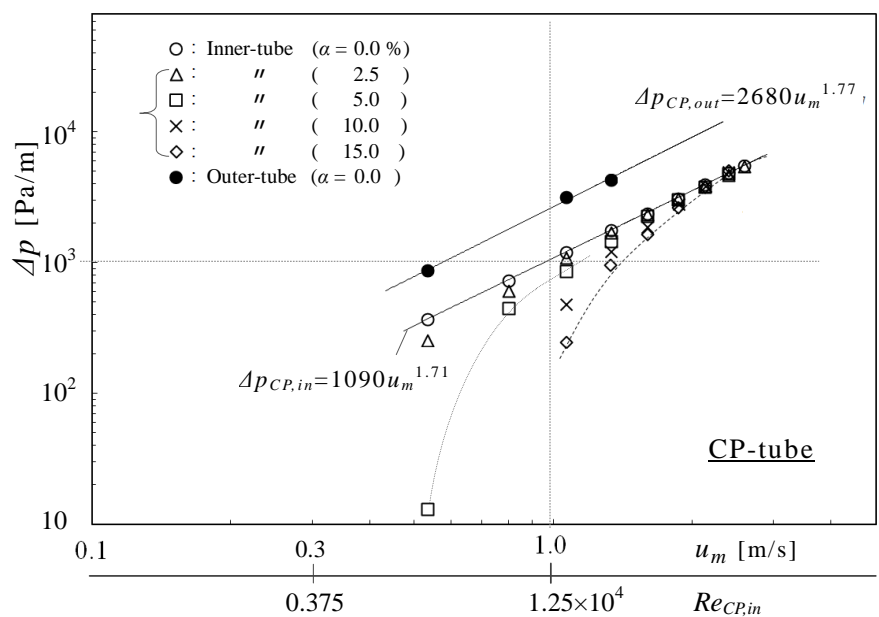

Fig.6 Pressure loss $\Delta p$ of single- and two-phase flows and $u_{m}$ or $R e_{C P, i n}(\mathrm{CP}$-tube)

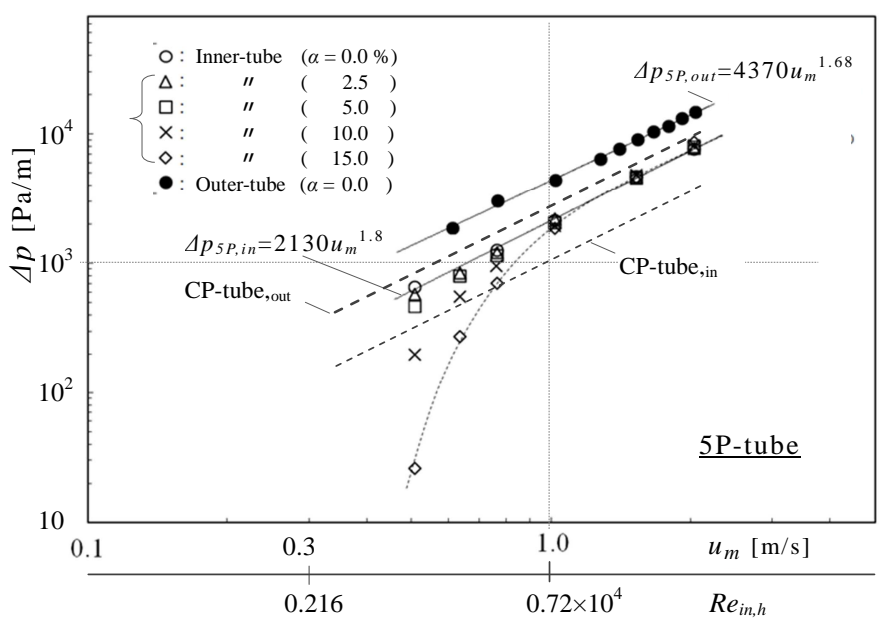

Fig. 7 Pressure loss $\Delta p$ of single- and two-phase flows and $u_{m}$ or $R e_{i n, h}$ (5P-tube) 
Equation (4) agrees well with Blasius Equation. However, with a decrease in the apparent void fraction for the bubbly flow, $\Delta p_{C P, i n}$ decreases rapidly in the low velocity region of $u_{m}<2.0 \mathrm{~m} / \mathrm{s}$.

$\Delta p_{C P \text {,out }}$ is much larger than $\Delta p_{C P \text {, in }}$ because of a large wetted perimeter.

Figure 7 shows the pressure losses in the inner and outer pipes of the $5 \mathrm{P}$-tube $\left(\Delta p_{5 P \text {,in }}\right.$ and $\Delta p_{5 P \text {,out }}$, respectively). $\Delta p_{5 P \text {, out }}$ is the value of pressure loss per single pipe. $\Delta p$ for single-phase water flow $(\alpha=0.0 \%)$ decreases exponentially with decreasing $u_{m}$ and can be expressed as

$$
\begin{aligned}
& \Delta p_{5 P, \text { in }}=2130 u_{m}^{1.8}, \quad \Delta p_{5 P, \text { out }}=4370 u_{m}^{1.68} \\
& \text { where, } \Delta p_{5 P, \text { in }}, \Delta p_{5 P, \text { out }}:[\mathrm{Pa} / \mathrm{m}], u_{m}:[\mathrm{m} / \mathrm{s}]
\end{aligned}
$$

In the case of bubbly flow, when $u_{m}<1.0 \mathrm{~m} / \mathrm{s}$ (low velocity region) $\Delta p_{5 p \text {,in }}$ decreases rapidly with a decrease in the apparent void fraction. For example, at $u_{m}=0.5 \mathrm{~m} / \mathrm{s}$ and the value of $\Delta p_{5 p \text {,in }}$ for $\alpha=15 \%$ is approximately $1 / 27$ th of its value for $\alpha=0.0 \%$. The primary reason for this is the definition of $\alpha$, since an increase in $\alpha$ implies a decrease in the volumetric flow rate of water and decrease in the wall friction due to air bubbles.

Figure 8 shows the pressure losses in the inner and outer pipes of the 6P-tube. $\Delta p$ for $\alpha=0.0 \%$ decreases exponentially with decreasing $u_{m}$ and can be expressed as

$$
\Delta p_{6 P, \text { in }}=2012 u_{m}{ }^{1.75}, \quad \Delta p_{6 P, \text { out }}=6010 u_{m}{ }^{1.73}
$$

where, $\Delta p_{6 P \text {, in }}, \Delta p_{6 P, \text { out }}:[\mathrm{Pa} / \mathrm{m}], u_{m}:[\mathrm{m} / \mathrm{s}]$

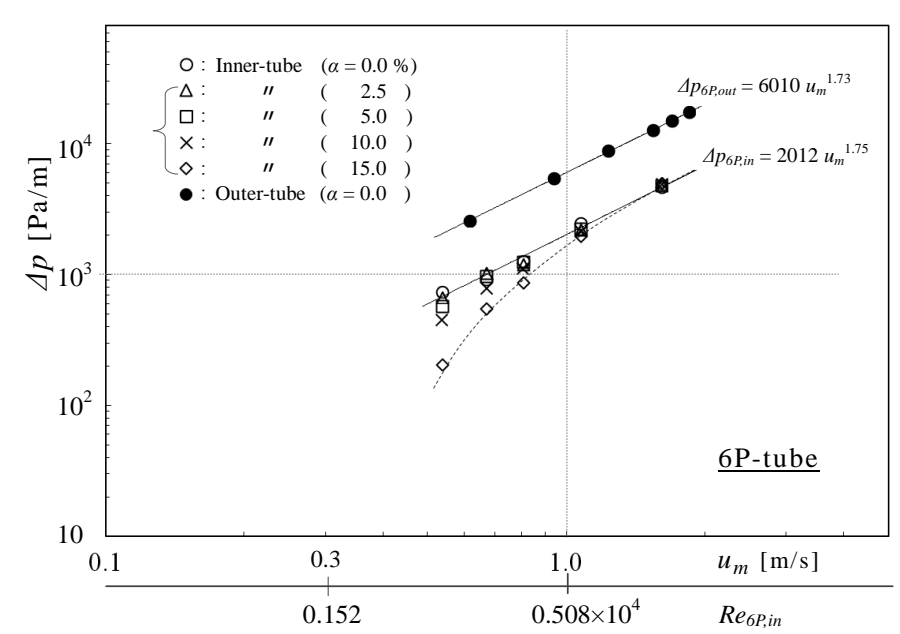

Fig. 8 Pressure loss $\Delta p$ of single- and two-phase flows and $u_{m}$ or $R e_{6 P, i n}(6 \mathrm{P}-$ tube)

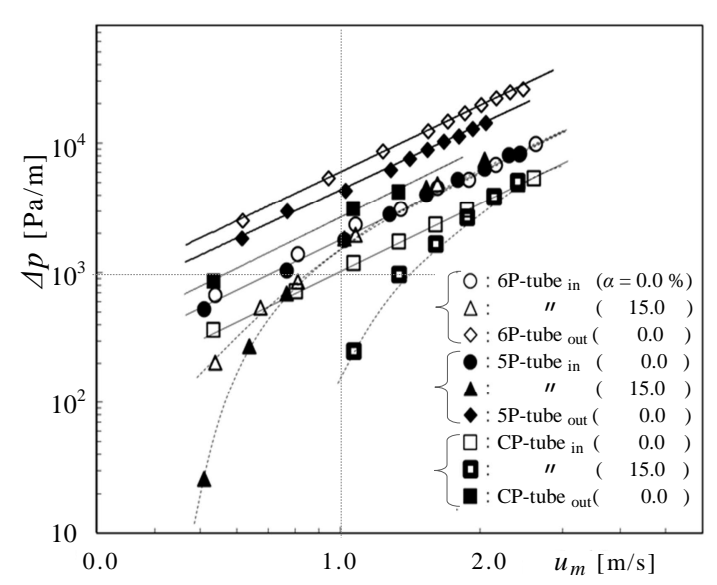

Fig.9 Pressure loss $\Delta p$ of single- and twophase flows and $u_{m}$ (5P-tube)

The pressure losses for $\alpha=0.0 \%$ in the inner pipes of the 5P- and 6P-tube are larger than that of the CP-tube. For example, the values of $\Delta p$ at $u_{m}=1.0 \mathrm{~m} / \mathrm{s}$ are 1.95 and 1.84 times of its value for CP-tube, respectively. There is no great difference between the $5 \mathrm{P}$ - and $6 \mathrm{P}$-tubes.

However, total pressure losses for $\alpha=0.0 \%$ in the outer pipes of the 5P-and 6P-tube are much larger than that of the CP-tube. For example, the values of $\Delta p$ at $u_{m}=1.0 \mathrm{~m} / \mathrm{s}$ are 8.1 and 13.41 times of its value for CP-tube, respectively. A large pressure loss reduces the heat transfer efficiency.

In Figure 9, the pressure losses in the 6P-, 5P- and CP-tubes, for $\alpha=0.0 \%$ and $15 \%$ are shown for reference.

\subsection{Heat transfer and mean Nusselt number}

This study experimentally examined the heat transfer characteristics of a counter flow heat exchanger with a petalshaped double tube, for gas-liquid bubbly flow. 


\subsubsection{Conventional double tube, CP-tube}

Figure 10 shows the heat transfer rate $Q$ in a CP-tube for $\alpha=0 \sim 15 \%$ and $R e_{i n, h}=(0.5 \sim 1.5) \times 10^{4}$. The flow rate in the outer pipe $V_{\text {out }}$ is $8.0 \mathrm{l} / \mathrm{min}$. $Q[\mathrm{~kW} / \mathrm{m}]$ increases with increasing $R e_{i n, h}$ and can be expressed as a linear function of $R e_{i n, h}[$ Equation (7)].

Further, $Q[\mathrm{~kW} / \mathrm{m}]$ decreases gradually with increasing $\alpha$. This depends on the decrease in heat capacity of the flow with increasing $\alpha$.

Figure 11 shows the relation between mean Nusselt number $N u$ and $R e_{i n, h}$ for the CP-tube. $N u$ in Equation (3) was obtained from the heat transfer coefficient $h_{i}$ which was obtained by measurements of $Q$ and Wilson plot method (Rose, 2004). $N u$ increases exponentially with increasing $R e_{i n, h}$ and can be expressed as a power function of $R e_{i n, h}$ [Equation (7)]. The straight lines in Figure 11 express each relation of $\mathrm{Nu}$ in Equation (7).

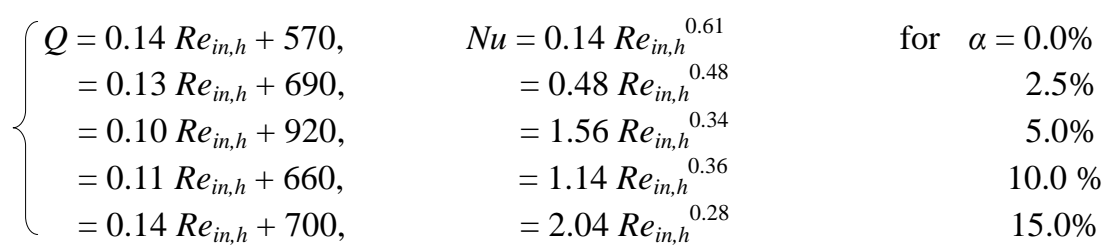

where, $Q:[\mathrm{W} / \mathrm{m}]$

Figure 12 shows the relation between $N u$ and $\alpha . N u$ increases with increasing $\alpha$, and then decreases after reaching a maximum value. It can be concluded that a small amount of air bubbles increases the flow fluctuation and thereby improve heat transfer performance.

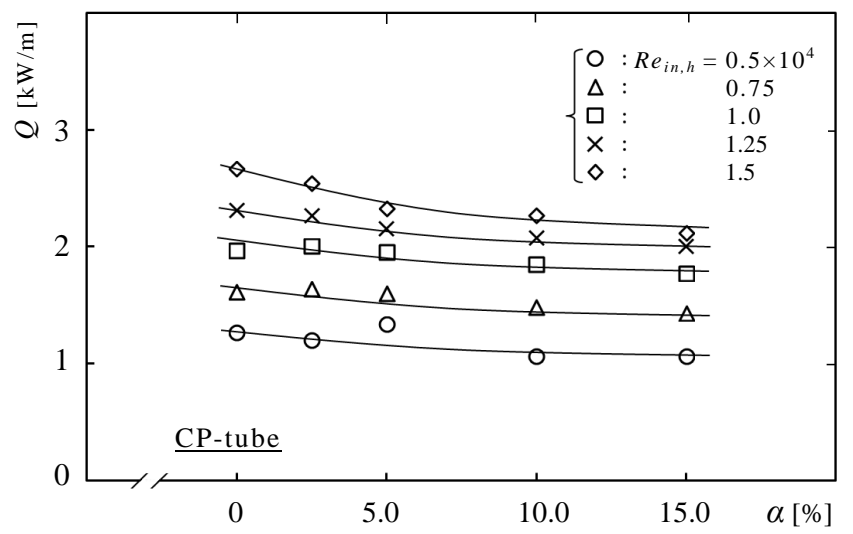

Fig.10 Heat transfer $Q$ and apparent void fraction $\alpha$ (CP-tube)

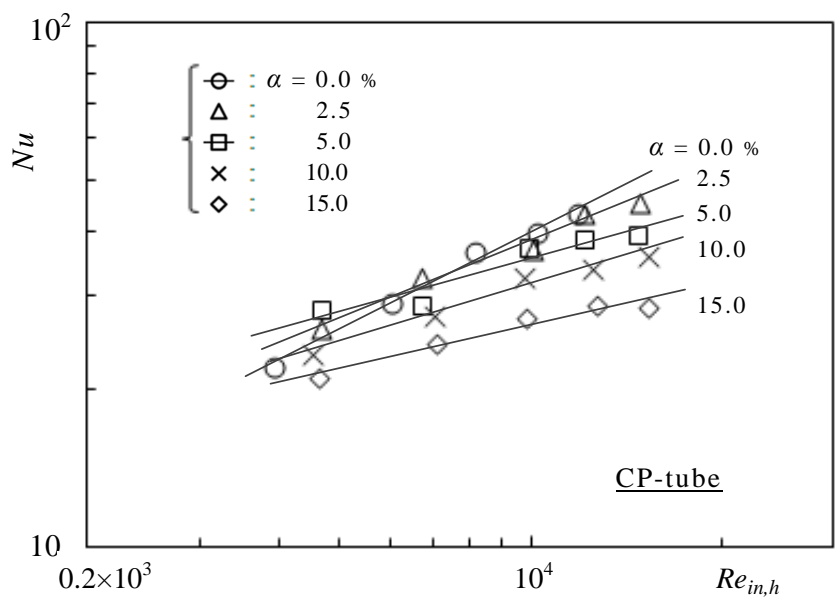

Fig. 11 Nusselt number $N u$ and $R e_{i n, h}$ (CP-tube)

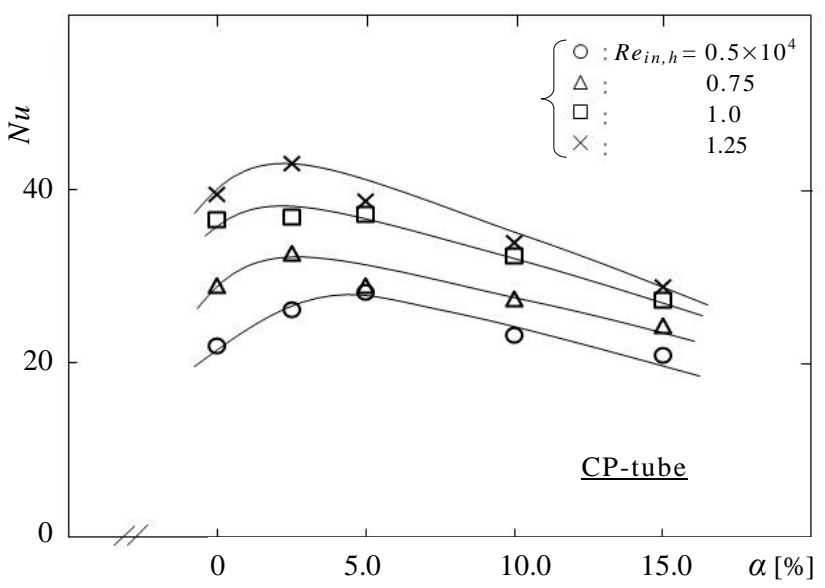

Fig.12 Nusselt number $N u$ and $\alpha$ (CP-tube) 


\subsubsection{Petal-shaped double tube, 5P-tube}

This section compares the heat transfer characteristics of the 5P-tube with those of the CP-tube.

Figure 13 shows the heat transfer $Q[\mathrm{~kW} / \mathrm{m}]$ of the 5P-tube for $\alpha=0 \sim 15 \%$ and $R e_{i n, h}=(0.5 \sim 1.5) \times 10^{4}$. The flow rate in the outer pipe is constant at $V_{\text {out }}=8.0 \mathrm{l} / \mathrm{min}$. $Q$ increases with increasing $R e_{i n, h}$ and can be expressed as a linear function of $R e_{i n, h}$ [Equation (8)]. $Q$ [kW/m] is almost constant and does not vary with $\alpha$. This is so because in bubbly

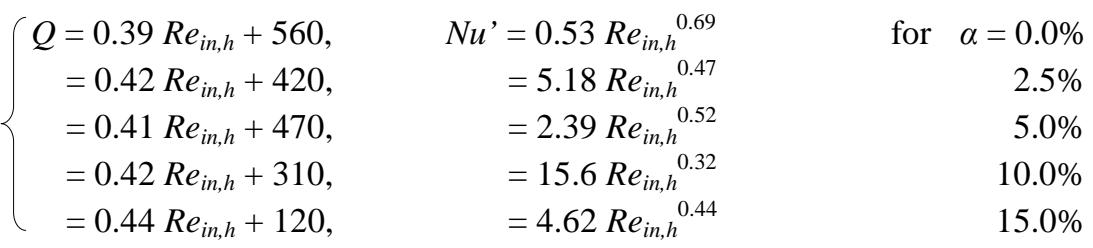

where, $Q:[\mathrm{W} / \mathrm{m}], N u^{\prime}=N u / A o, A o:$ heat transfer area $\left(=L \times p_{i n}\right)$

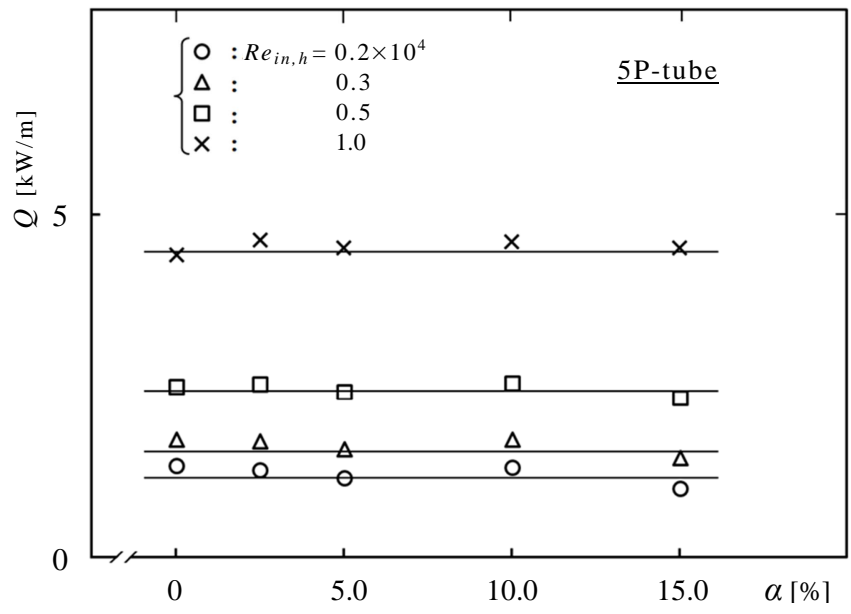

Fig.13 Heat transfer $Q$ and apparent void fraction $\alpha$ (5P-tube)

flow, almost all air bubbles flow through the central region rather than through the petal-shaped area because of a large flow resistance. Therefore, the heat transfer rate does not vary with $\alpha$.

Figure 14 shows the relationship between $N u$ ' and $R e_{i n, h}$ for the 5P-tube. The figure also shows the results of $N u$ for the CP-tube, for $\alpha=0.0 \%$, as obtained by Dittus-Boelter (1930). These results agree well with the experimental results. $N u^{\prime}$ increases exponentially with increasing $R e_{i n, h}$ and can be expressed as a power function of $R e_{i n, h}$ [Equation (8)]. The straight lines in Figure 14 express the relations of $N u$ ' in Equation (8) for $\alpha=0,2.5$ and $5.0 \%$.

Figure 15 shows the relation between $N u^{\prime}$ and $\alpha . N u^{\prime}$ increases with an increase in both $\operatorname{Re}_{i n, h}$, and $\alpha$ and then decreases after reaching the maximum value at $\alpha=2.5 \%$. It can be concluded that a small amount of air bubbles increases the flow fluctuation and thereby improve the heat transfer performance.

\subsubsection{Heat transfer characteristics of petal-shaped double tube}

\section{(a) Mean Nusselt number}

Figures 16 and 17 show examples of the mean Nusselt number for bubbly flow, for $\alpha=2.5 \sim 15.0 \%$, in the cases of the $6 \mathrm{P}-, 5 \mathrm{P}-$, and $\mathrm{CP}$-tubes.

Figure 16 shows $\mathrm{Nu}$ ' for the 6P-, 5P-, and $\mathrm{Nu}$ for CP-tubes, for $\alpha=0.0 \%$ and $2.5 \%$. In all cases, $\mathrm{Nu}$ ' values for the $6 \mathrm{P}-$, and 5P-tubes are greater than the corresponding values for the CP-tube. For example, at $\operatorname{Re}_{i n, h}=1.0 \times 10^{4}$ and $\alpha=$ $2.5 \% \mathrm{Nu}$ ' values for the 6P- and 5P-tubes are 1.77 and 3.1 times, respectively, of the corresponding values for the CP-tube for $\alpha=0.0 \%$. This result is due to a larger wetted perimeter and the generation of longitudinal vortex and turbulence at the narrow petal-shaped area (Fukushima, 2002) in the cases of the 6p- and 5P-tubes. $\mathrm{Nu}$ ' for the 5P-tube is larger than that for the 6P-tube, because the petal-shaped cross-sectional area of the former is larger than that of the latter. Further, the decrease in flow velocity in the 5P-tube is smaller than that in the 6P-tube.

Figure 17 shows $N u$ ' for $\alpha=0.0 \%$ and 5.0\%. In all cases, $N u^{\prime}$ values for the 6P- and 5P-tubes are greater than the 


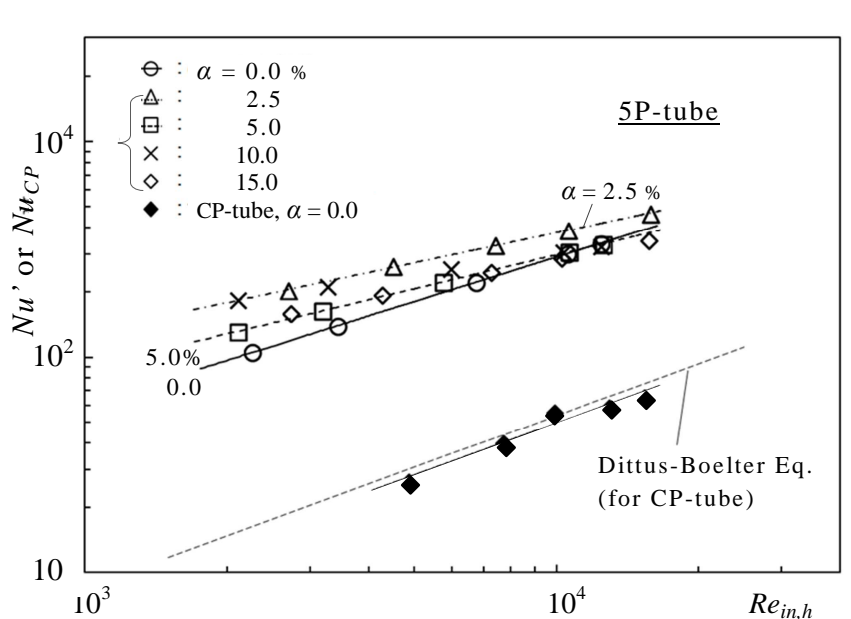

Fig. 14 Nusselt number $N u^{\prime}$ and $R e_{i n, h}(5 \mathrm{P}$-tube)

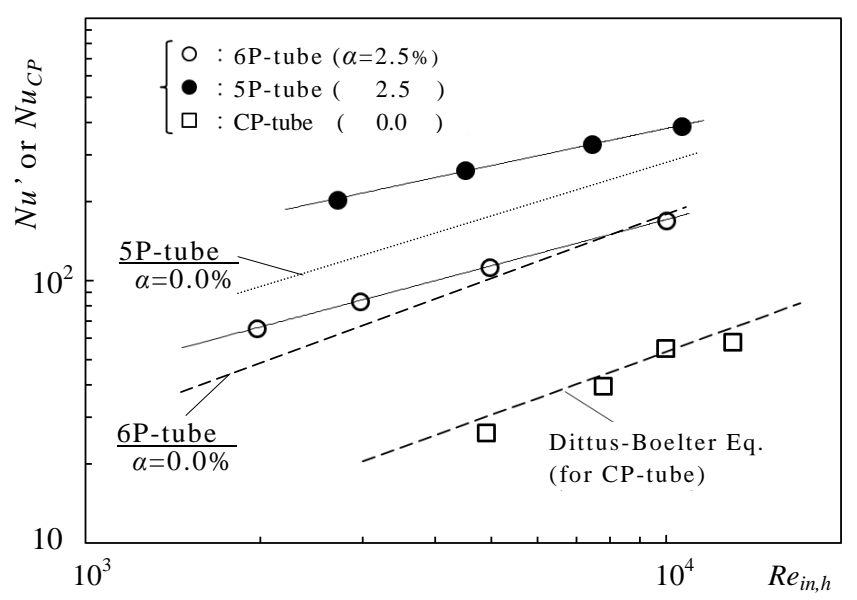

Fig. 16 Nusselt number $N u$ ' and $R e_{i n, h}(\alpha=2.5 \%)$

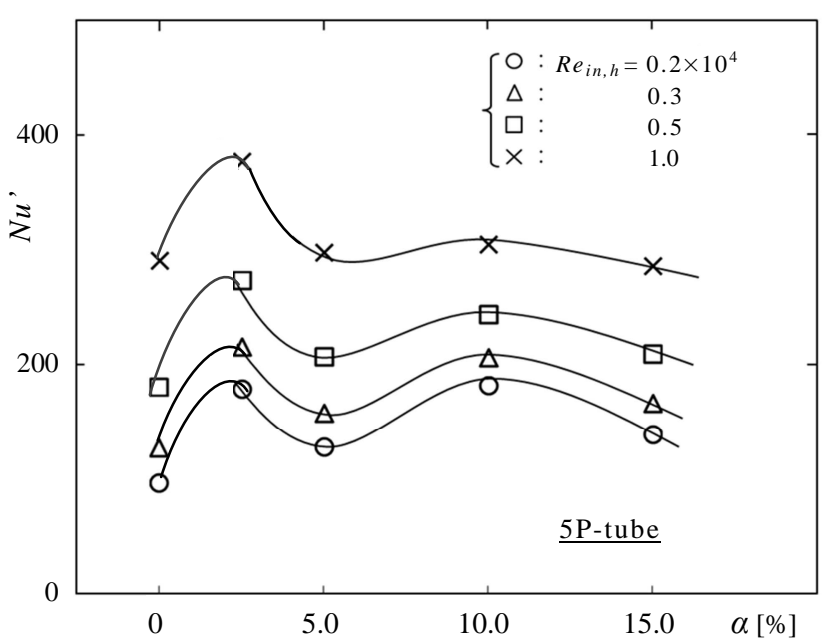

Fig. 15 Nusselt number $N u^{\prime}$ and $\alpha$ (5P-tube)

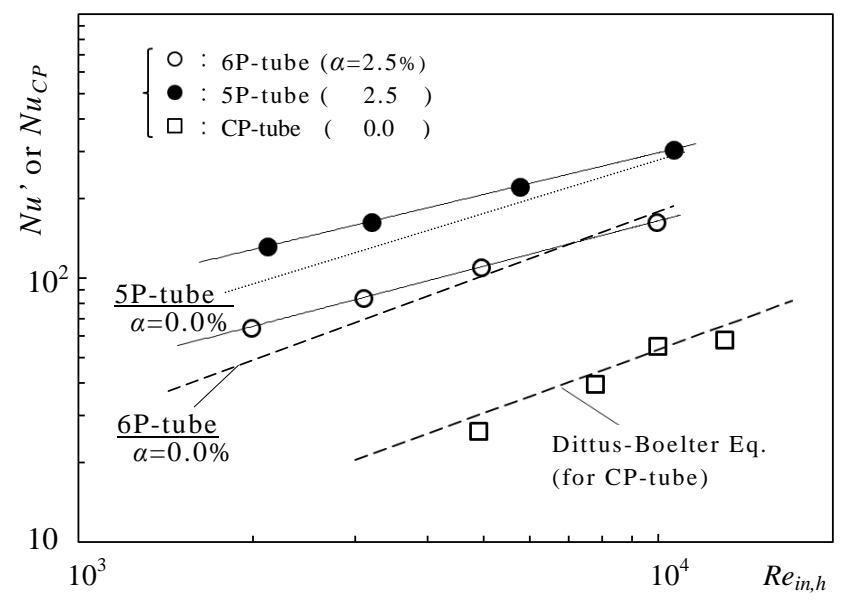

Fig. 17 Nusselt number $N u^{\prime}$ and $\operatorname{Re}_{i n, h}(\alpha=5.0 \%)$

corresponding values of $\mathrm{Nu}$ for the CP-tube. For example, at $R e_{i n, h}=1.0 \times 10^{4}$ and for $\alpha=5.0 \% \mathrm{Nu}$ ' values are 1.49 and 2.87 times, respectively, of those of the CP-tube for $\alpha=0.0 \%$.

\section{(b) Heat transfer efficiency}

The heat transfer efficiency can be expressed as

$\eta=\frac{N u^{\prime} / N u_{C P}^{\prime}}{V \Delta P /(V \Delta P)_{C P}}$

where, $V$ is the volumetric flow rate.

Figure 18 shows the heat transfer efficiency $\eta$ of the 6P- and 5P-tubes for single-phase water flow for $\alpha=0.0 \%$. The efficiency of the tubes decreases with increasing $R e_{i n, h}$ because of the increasing flow resistance. The efficiency of the 6P-tube is less than unity because of a large flow resistance, especially in the outer pipe. The flow resistance of the 6P-tube is larger than that of the CP-tube. The 5P-tube has a higher efficiency $\left[\eta=1.82 \sim 1.1\right.$ at $\left.\operatorname{Re}_{i n, h}=(0.6 \sim 1.0) \times 10^{4}\right]$ than the $6 \mathrm{P}$-tube, because it has a much smaller flow resistance.

Figures 18 and 19 show examples of the heat transfer efficiency $\eta$ for bubbly flow at $R e_{i n, h}=(0.6 \sim 1.2) \times 10^{4}$ for the $6 \mathrm{P}$ - and 5 p-tubes.

Figures 19, 20 show $\eta$ for two-phase bubbly flow at $R e_{i n, h}=0.6$ and $1.0 \times 10^{4}$, respectively. In all cases, the efficiency reaches the maximum value at $\alpha=2.5 \%$. A small amount of bubbles cause a flow disturbance and there by 


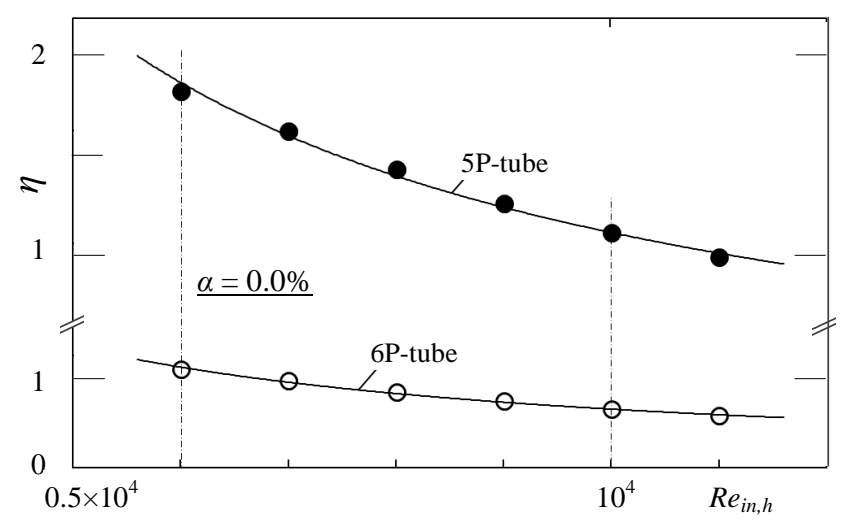

Fig. 18 Heat transfer efficiency $\eta$ of 5P- and 6P-tubes for single-phase flow $(\alpha=0.0 \%)$

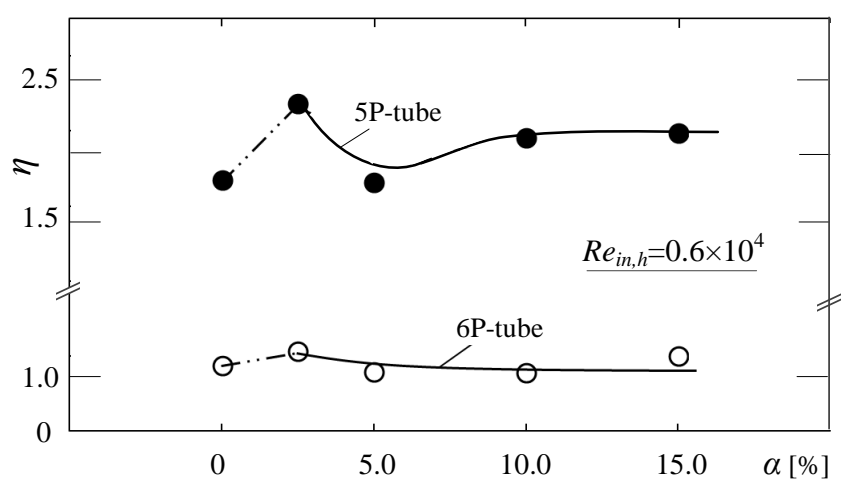

Fig.19 $\eta$ of 5P- and 6P-tubes for two-phase flow $\left(R e_{i n, h}=0.6 \times 10^{4}\right)$

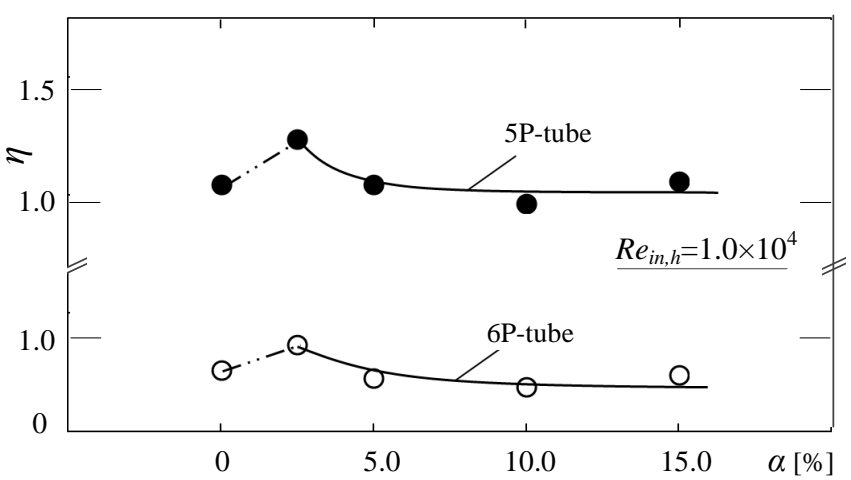

Fig.20 $\eta$ for two-phase flow of 5P- and 6P-tubes $\left(R e_{i n, h}=1.0 \times 10^{4}\right)$

improve the heat transfer efficiency. For example, for $\alpha=2.5 \sim 15.0 \%$ at $R e_{i n, h}=0.6 \times 10^{4}$, the heat transfer efficiencies of the 5P- and 6P-tubes are approximately 2.42 2.15 and 1.36 1.3, respectively, whereas at $R e_{i n, h}=1.0 \times 10^{4}$, the heat transfer efficiencies are approximately $1.3 \sim 1.1$ and 1.0 0.6, respectively.

\section{Conclusions}

This study experimentally examined the flow and heat transfer characteristics of a petal-shaped double tube for both single-phase water and two-phase air-water flows. Major results found are as follows:

(1) The heat transfer of a petal shaped double tube is much larger than that of a conventional circular double tube, CPtube, because it has a larger heat transfer area. But, a petal shaped double tube has a significantly larger flow resistance than the CP-tube.

A small amount of air bubbles can decrease the flow resistance.

(2) The mean Nusselt number $N u$ ' of a petal-shaped double tube is much larger than that of a conventional circular double tube, CP-tube.

For example, for single-phase water flow $N u$ ' values for the $6 \mathrm{P}$ - and $5 \mathrm{P}$-tubes, at $R e_{i n, h}=1.0 \times 10^{4}$ for $\alpha=0.0 \%$ are 1.77 and 3.1 times of those of the CP-tube, respectively. Further, for two-phase air-water flow, $N u$ ' values for the $6 \mathrm{P}$ and 5P-tubes for $\alpha=5 \%$ are 1.49 and 2.87 times those of the CP-tube, respectively.

(3) The heat transfer efficiencies $\eta$ of the 6P- and 5p-tubes, at $R e_{i n, h}=(0.5 \sim 1.0) \times 10^{4}$ and for $\alpha=0.0 \%$ are $1.1 \sim 0.56$ and 1.82 1.1, respectively.

For two-phase flow, at $R e_{i n, h}=0.6 \times 10^{4}$ and for $\alpha=2.5 \sim 15 \%$, the heat transfer efficiencies of the 6P- and 5P-tubes are approximately $1.36 \sim 1.3$ and $2.42 \sim 2.15$, respectively, whereas at $R e_{i n, h}=1.0 \times 10^{4}$, the efficiencies are approximately 1.0 0.6 and 1.3 1.1, respectively.

A small amount of air bubbles improve the heat transfer efficiency by decreasing the flow resistance. 


\section{Acknowledgements}

The supports for this work from Chubu Electric Power Co., Inc., Japan and Tokai Shipbuilding \& Engineering Co., Ltd., Japan are gratefully acknowledged.

\section{References}

Dittus, F. W. and Boelter, L. M. K., Heat transfer in automobile radiators of tubular type, Univ. of California Publications in Engineering, Vol.2 (1930), pp.443-461.

Fukushima, N. and Kasagi, N., Heat transfer and friction characteristics in turbulent rhombic duct flows, Proceedings of Japan Heat Transfer Symposium, (2002), pp.595, 596.

Fuskele, V. and Sarviya, R. M., Experimental investigation of heat transfer enhancement in double pipe heat exchanger twisted dense wire mesh insert, International Journal of Advanced Engineering Research and Studies, Vol.1 (2012), pp.5-9.

Kimura, H. and Ito, M., Evaporation heat transfer in a low flow region of horizontal pipe with a spiral groove, Transactions of Japan Society of Mechanical Engineers, JSME, B, Vol.47, No.413 (1981), pp.149-157.

Nagashima, T., Ishi, T., Tachibana, N., Katano, I., Chiba, A., Sumida, R., Kawaguchi, A. and Sobue, K., Heat transfer characteristics of multi-petal double tube heat exchanger, Technical data, Nishiyama Seisakusho CO., LTD, Japan (2010).

Ozawa, R., Flow and heat transfer of two-phase bubbly flow through petal shaped double tube, Master's thesis of Mie University, Japan (2015)

Promvonge, P., Pethkool, S. Pimsarn, M. and Thianpong, C., Heat transfer augmentation in helical-ribbed tube with double twisted tape, International Communication in Heat and Mass Transfer,Vol.39 (2012), pp.953-959.

Rose, J. W., Heat-transfer coefficients, Wilson plots and accuracy of thermal measurements, Experimental Thermal and Fluid Science, Vol.28 (2004), pp.77-86.

Shakouchi, T., Oshima, Y., Kawashima, Y, Tsujimoto, K. and Ando, T., Compact heat exchanger by petal-shaped special double tube, Proceedings of The $23^{\text {rd }}$ International Symposium on Transport Phenomena, CD-ROM (2012), pp.1-4.

Shakouchi, T., Ozawa, S., Iwasaki, F, Tsujimoto, K. and Ando, T., Flow and heat transfer of petal shaped double tube -Effects of pipe geometry-, Springer Proceedings in Physics, Vol.185, Proceedings of The $5^{\text {th }}$ International Conference on Jets, Wakes and Separated Flows (ICJWSF-2015), Springer (2016). 